bly counteracted by administration of the moulting hormone (Table II). This suggests. that DAEA causes lack of moulting hormones due to an additional block in the metabolic pathway from cholesterol to moulting hormones. Studies designed to further our understanding of the effects of DAEA on sterol metabolism in Bombyx are now in progress.

Acknowledgement We are grateful to Dr. H. Mori, Teikoku Hormone Mfg. Co., Ltd., for gift of: 5-dehydroepiandrosterone, and to Prof. K. Simura, this University, and Dr. T. Kurasawa, Miyagi Prefec-ture Sericultural Experiment Station, for gift of silkworms.

Pharmaceutical Institute,

Tohoku University,

Aobayama, Sendai

Received October 25, 1971

\author{
HiRoshi Hikino \\ Yasushi OHizumi \\ TомоKo SaITo \\ ETSUKo NaKamura \\ Tsunematsu Takemoto
}

\title{
The Stereochemistry of Enzymatic Aromatization of 19-Norsteroids
}

The bioconversion of $\mathrm{C}_{\mathbf{1 9}}$ steroids into estrogens requires two general steps: (1) hydroxylation and subsequent loss of the $\mathrm{C}-19$ methyl group, and (2) removal of hydrogens from both $\mathrm{C}-1$ and $\mathrm{C}-2$ resulting in a double-bond in ring A. ${ }^{1)}$ The 19-norsteroids also serve as. estrogen precursors in the placental and ovarian tissues ${ }^{2)}$ and hence are useful model compounds for the study of the aromatization reaction. In addition the metabolism of the19-norsteroids is of particular interest in itself, since they are widely used for the contraceptiveand chemotherapeutic purposes. Recently the $\beta$-cis nature of $\mathrm{C}-1,2$ dehydrogenation in the enzymatic aromatization was established with $\mathrm{C}_{\mathbf{1 9}}$ steroids. ${ }^{3}$ ) Concerning the 19-norsteroids, however, the evidence only for the elimination of the $1 \beta$-hydrogen in this process. has been demonstrated. ${ }^{4}$ We now wish to report on the stereochemistry of hydrogen loss from C-2 during the placental aromatization of estr-4-ene-3,17-dione.

An initial project was focused to the synthesis of the substrates stereospecifically labeled with tritium in the $2 \beta$ and $2 \alpha$ positions of estrenedione. The preparation of the desired substrates was carried out along the way which had already been developed for epimeric 2-deuterioestr-4-ene-3,17-diones. ${ }^{5)} \quad$ Reduction of $2 \beta, 3 \beta$-epoxyestrane-5 $\beta, 17 \beta$-diol (II) derivable from estr-2-ene-5 $5,17 \beta$-diol (I) with $\left[{ }^{3} \mathrm{H}\right] \mathrm{LiAlH}_{4}$ yielded the $\left[2 \alpha-{ }^{3} \mathrm{H}\right] 3 \beta, 5 \beta, 17 \beta$-triol (III). Usual acetylation and dehydration with thionyl chloride in pyridine gave $\left[2 \alpha^{-}{ }^{3} \mathrm{H}\right]$ estr-4-ene-

1) P. Talalay, Ann. Rev. Biochem., 34, 347 (1965); R.A. Meigs and K.J. Ryan, J. Biol. Chem., 246, 83 (1971) and references quoted therein.

2) L.L. Engel, J. Alexander, and M. Wheeler, J. Biol. Chem., 231, 159 (1958); J.B. Brown and H.A.F. Blair, Proc. Roy. Soc. Med., 53, 433 (1960); H. Breuer, U. Dardenne, and W. Nocke, Acta Endocrinol., 33, 10 (1960); H. Langecker, ibid., 37, 14 (1961); P.K. Besch, D.J. Watson, N. Vorys, and R.D. Barry, Biochim. Biophys. Acta, 69, 417 (1963); J.D. Townsley and H.J. Brodie, Biochem. J., 101, 25c (1966); idem, Biochim. Biophys. Acta, 144, 440 (1967).

3) J. Fishman and H. Guzik, J. Am. Chem. Soc., 91, 2805 (1969); J. Fishman, H. Guzik, and D. Dixon, Biochemistry, 8, 4304 (1969); H.J. Brodie, K.J. Kripalani, and G. Possanza, J. Am. Chem. Soc., 91, $1241(1969)$.

4) J.D. Townsley and H.J. Brodie, Biochemistry, 7, 33 (1968).

5) T. Nambara, H. Hosoda, T. Anjyo, M. Yamauchi, and J. Mohri, Chem. Pharm. Bull. (Tokyo), 20, 287 (1972). 
$3 \beta, 17 \beta$-diol diacetate (IV). Hydrolysis with alkali and subsequent oxidation with chromium trioxide-pyridine complex afforded one of the desired substrates, $\left[2 \alpha-{ }^{3} \mathrm{H}\right]$ estr-4-ene-3,17-dione (V). Hydroboration of I with tritiated diborane, which was generated from lithium aluminum tritiide and boron trifluoride, followed by oxidation gave the $\left[2 \beta-{ }^{3} \mathrm{H}\right] 3 \beta, 5 \beta, 17 \beta$-triol (VI). Transformation of VI into the other substrate, $\left[2 \beta-{ }^{3} \mathrm{H}\right]$ estr-4-ene-3,17-dione (VII), was performed in the same manner as described above for the $2 \alpha$-labeled substrate. These tritiated compounds were mixed with an appropriate amount of $\left[4^{-14} \mathrm{C}\right]$ estr-4-ene-3,17-dione and repeatedly recrystallized to constant isotope ratio, respectively.

TABLE I. Tritium Loss of Products and Substrates in Placental Aromatization

\begin{tabular}{lcc}
\hline & $\left.{ }^{3} \mathrm{H} /{ }^{14} \mathrm{C}^{a}\right)$ & $\%{ }^{3} \mathrm{H}$ lost \\
\hline$\left[2 \alpha{ }^{3} \mathrm{H}\right]$ Estr-4-ene-3,17-dione (V) & 37.8 & 20 \\
Estrone & 30.1 & \\
$1 \beta$-Hydroxyestr-4-ene-3,17-dione & 30.3 & \\
Recovered substrate & 35.6 & 79 \\
{$\left[2 \beta\right.$ - $\left.{ }^{3} \mathrm{H}\right]$ Estr-4-ene-3,17-dione (VII) } & 37.6 & \\
Estrone & 8.0 & \\
$1 \beta$-Hydroxyestr-4-ene-3,17-dione & 29.2 & 35.0 \\
Recovered substrate & & \\
\hline
\end{tabular}

a) expressed as ratio of disintegration per minute (dpm)

The labeled substrates were incubated with human placental preparation according to the method of Ryan.6) The incubation mixture consisted of $50 \mu \mathrm{g}$ of the steroid substrate, placental $10000 \times \boldsymbol{g}$ supernatant equivalent to $16 \mathrm{~g}$ wet weight of tissue and NADPH-generating system suspended in $11 \mathrm{ml}$ of $0.05 \mathrm{~m}$ phosphate buffer, $\mathrm{pH} 7.0$. After incubation at $37^{\circ}$ for $1 \mathrm{hr}$, the mixture was extracted with ethyl acetate and the extract was separated by thin-layer chromatography on silica gel. The products and unchanged substrate thus obtained were diluted with carrier and then recrystallized to constant specific activity, respectively.

The results of the incubations are collected in Table I. Estrone formed from VII with the label in the $2 \beta$-position exhibited a $79 \%$ loss of tritium. In contrast the $2 \alpha$-labeled substrate (V) lost only $20 \%$ tritium. These figures unambiguously tell us that the hydrogen loss from C-2 in the aromatization process is stereoselectively $\beta$ and in consequence $\mathrm{C}-1,2$ hydrogen elimination is $\beta$-cis. The $1 \beta$-hydroxylated products obtained from both incubations showed almost the same tritium content with a slight decrease. The retention of tritium in the recovered substrates implies that the hydrogen removal from $\mathrm{C}-2$ is not a reversible process.

Acknowledgement We are grateful to Dr. C.M. Siegmann, N.V. Organon, Netherlands, for the generous gift of $1 \beta, 17 \beta$-dihydroxyestr-4-en-3-one. This work was supported in part by a Grant-in-Aid for Scientific Research from the Ministry of Education, which is gratefully acknowledged.

\author{
Pharmaceutical Institute, \\ Tohoku University, \\ Aobayama, Sendai
}

Toshio Nambara

TAKako ANJYo

Hiroshi Hosoda

Received November, 6, 1971

6) K.J. Ryan, J. Biol. Chem., 234, 268 (1959). 